\title{
FUNÇÕES URBANAS NA FAIXA DE FRONTEIRA AMAZÔNICA: CENTRALIDADE DE NHAMUNDÁ (AM) E SEUS SISTEMAS TERRITORIAIS ${ }^{1}$
}

\author{
THE URBAN FUNCTIONS ALONG THE AMAZON'S BORDER STRIP: \\ CENTRALITY OF NHAMUNDÁ (AM) AND ITS TERRITORIAL SYSTEMS
}

Estevan BARTOLI ${ }^{2}$

\begin{abstract}
Resumo: O objetivo do artigo é entender os papeis e funções urbanas de Nhamundá, averiguando como afetam a área municipal e a faixa de fronteira. Inicialmente descrevemos como o sítio urbano (base física) e a posição de sede em relação à rede urbana regional são condicionantes dos tipos de uso do solo, concentrando na faixa sul do município maior parte da circulação e aglomerados humanos (rurais e urbanos). No segundo item abordamos como a circulação regional insere Nhamundá nas redes urbanas do Amazonas e Pará, possibilitando entrada de produtos que abastecem a cidade e seus entornos. No terceiro momento descrevemos a centralidade comercial e os principais sistemas territoriais locais através do modelo Sistema Territoriais Urbano-ribeirinho (STUR). Conclui-se que junto à frágil composição da economia local e sua situação na rede urbana importando produtos, os papéis de mediação exercidos pela cidade são ainda insuficientes quanto ao processamento de recursos regionais.
\end{abstract}

Palavras-Chaves: Sítio urbano; Situação; Mediações urbanas; Sistemas territoriais; Faixa de fronteira.

\begin{abstract}
The aim of the article is to understand Nhamundá's urban roles and functions, investigating how they affect the municipal area and the border strip. At first it was described how the urban site (physical base) and the position of headquarters in relation to the regional urban network are conditioning factors of types of land use, concentrating most of the circulation and human settlements (rural and urban) in the southern part of the municipality. In the second item it was discussed how the regional circulation inserts Nhamundá into the urban networks of Amazonas and Pará, causing the entry of products that supply the city and its surroundings. At the third moment it was described the commercial centrality and the main local territorial systems using the Urban-riverside Territorial System (STUR) model. It was concluded that, together with the fragile composition of the local economy and its your situation in the urban network importing products, the mediation roles exercised by the city are still insufficient as regards in the processing of regional resources.
\end{abstract}

Keywords: Site; Urban mediations; Territorial systems; Border strip.

\section{Introdução}

O presente artigo faz parte da primeira etapa da análise empreendida pelo Núcleo Estadual de Integração e Desenvolvimento da Faixa de Fronteira do Estado do Amazonas (NIFFAM), relativa à sub-região do baixo Amazonas ${ }^{3}$. O NIFFAM foi criado por um grupo

\footnotetext{
${ }^{1}$ Financiamento concedido através de Bolsa Produtividade da Universidade do Estado do Amazonas (UEA)

${ }^{2}$ Professor da Universidade do Estado do Amazonas - ebartoli11@ gmail.com

${ }^{3}$ Denominamos no presente texto baixo Amazonas, a sub-região de planejamento composta pelos municípios de Urucará, Boa Vista do Ramos, Barreirinha, Maués, São Sebastião do Uatumã, Nhamundá e Parintins. Urucará e Nhamundá seriam os dois municípios com parte de seu território inseridos na faixa de Fronteira.
} 
multi-institucional com a tarefa de articular ações de integração e desenvolvimento na região fronteiriça do Amazonas. A análise no baixo Amazonas ocorre com parceria da Universidade do Estado do Amazonas (UEA - Campus de Parintins), através do Núcleo de Estudos Territoriais do Amazonas (NETAM) que vem realizando estudos sobre os municípios do baixo Amazonas no Projeto intitulado Rede urbana, Tipologia de Cidades e Sistemas Territoriais Urbano-ribeirinhos no Baixo Amazonas.

Criada por meio do Decreto $\mathrm{n}^{\circ} 32.729$, de 22 de agosto de 2012, o NIFFAM tem por finalidade coordenar ações e propor medidas que visem o desenvolvimento de iniciativas e a implementação de políticas públicas prioritárias à atuação do Governo Estadual na região fronteiriça, sob a coordenação da Secretaria de Estado de Desenvolvimento Econômico, Ciência, Tecnologia e Inovação - SEDECTI. O decreto considera a necessidade de fundamentar propostas de integração fronteiriça, controle e operacionalização de migrações, fortalecimento institucional e, desenvolvimento econômico, social e ambiental. Como atribuições, o NIFFAM deve planejar reuniões, colhendo e sistematizando demandas dos atores locais, elaborando projetos e articulando soluções no âmbito regional de demandas específicas.

Com dois municípios do baixo Amazonas inseridos na faixa de Fronteira, Nhamundá (AM) e Urucará (AM), o objetivo do artigo é entender as funções urbanas de Nhamundá, averiguando como tais características afetam a faixa de fronteira, que se desdobram em três objetivos específicos formando três subitens que estruturam o texto. Inicialmente descrevemos como o sítio municipal (base física) e a posição da sede em relação à rede urbana regional são hoje condicionantes dos tipos de uso do solo, concentrando na faixa sul do município a maior parte da circulação e dos aglomerados humanos (rurais e urbanos). A presença de jazidas minerais vem despertando atenção de setores dominantes e pressionando as Terras indígenas ao norte.

No segundo item abordamos como a circulação regional insere Nhamundá nas redes urbanas do Amazonas e Pará. Formada primordialmente pelo transporte fluvial, tipologias de embarcações e suas rotas demonstram como a cidade tem grande entrada de produtos que a abastece, com baixa produção rural e urbana fragilizando ainda mais a economia local. Parte das elites da cidade se beneficia dessa função de entreposto comercial, concentrando poder através do domínio do comércio e transporte.

No terceiro item descrevemos a centralidade comercial e os principais sistemas territoriais locais através do modelo Sistema Territorial Urbano-Ribeirinho (STUR). Com 
uma economia rural e urbana insuficiente, o município tem no funcionalismo público a maior base da receita. Forma-se uma economia popular como estratégia de sobrevivência através de intensa circulação sub-regional e interação de complementação com o capital mercantil urbano.

Os procedimentos metodológicos seguem a proposta presente em Bartoli (2017, 2018a, 2018b), de analisar a dinâmica territorial a partir do modelo Sistema Territorial Urbano-Ribeirinho (STUR),

O modelo analítico relativo ao Sistema Territorial Urbano-Ribeirinho (STUR) pretende preencher lacunas em pesquisas sobre os papéis de cidades na Amazônia, pois em cidades de dinâmica ribeirinha há dinamismo associado à formação da chamada "economia informal", que preferimos nomear como popular, averiguando: dados secundários relativos à densidade de ocupação do território e, trabalhos de campo descrevendo as principais redes de sujeitos locais (economia popular e capital mercantil dominante). Os critérios de análise do modelo STUR são detalhados neste item.

A análise do STUR contribui demonstrando: que a economia urbana incompleta suscita por parte dos citadinos a manutenção de vínculos territoriais com áreas diversas do entorno das cidades (comunidades, aldeias, assentamentos, etc.); as redes locais de sujeito utilizam das oportunidades existentes na cidade para reconstrução de territorialidades (considerando dimensões políticas, culturais, econômicas e com relações com a natureza local - BARTOLI, 2017); ocorre aumento da circulação sub-regional (transporte fluvial) com intensificação de complementaridades entre interiores e a cidade (BARTOLI, 2018a) e esta com a metrópole Manaus e demais redes regionais e nacionais; cidades reforçam centralidades e desempenham desenvolvimento de novas formas de distribuição de produtos industrializados, consumo urbano e absorção de recursos regionais, reordenando suas áreas de influência e reconfigurando o espaço intraurbano (BARTOLI, 2018b); as camadas populares do STUR ficam cada vez mais sujeitas ao domínio do capital mercantil local, incluindo relações e disputas escalares com outros municípios da rede (BARTOLI, 2019).

Conclui-se que junto à frágil composição da economia local e sua situação na rede urbana importando produtos, as funções de mediação exercidas pela cidade são ainda insuficientes quanto ao processamento de recursos regionais, servindo como indicadores iniciais para o aprofundamento de diagnósticos e a formulação de políticas públicas futuras para faixa de fronteira. 


\section{Sítio, posição de Nhamundá e a faixa de fronteira}

A extensa faixa de fronteira do Brasil abrange 11 unidades da federação e 588 municípios, dos quais 432 estão inteiramente dentro da faixa e 156 parcialmente. Esta faixa possui 15,9 mil $\mathrm{Km}$ de comprimento, $150 \mathrm{~km}$ de largura e área total de 1,4 milhão de $\mathrm{Km}^{2}$, o equivalente a 16,6\% do território brasileiro. Outra característica importante é que 502 municípios têm suas sedes municipais dentro da faixa e 86 fora dela, aumentando a responsabilidade territorial das cidades: fornecimento de serviços diversos, função de mercado local, preservação/conservação ambiental, entre outras funções.

Os municípios brasileiros com área total ou parcialmente localizada na faixa de fronteira estão sob legislação específica para áreas de segurança nacional (Lei N 6.634/1979, regulamentada pelo Decreto $\mathrm{N}^{\circ} 85.064 / 1980$ ), que é a faixa interna de $150 \mathrm{~km}$ de largura, paralela à linha divisória terrestre do território nacional. A Lei estabelece auxílios financeiros específicos por parte do governo federal e impede sem prévia autorização a concessão de terras públicas ou a construção de pontes, estradas e aeroportos, bem como a instalação de empresas de mineração. Nhamundá possui $659 \mathrm{Km}^{2}$ dentro da área de fronteira que corresponde a $4,7 \%$ de sua área municipal.

No estado do Amazonas, o predomínio do transporte fluvial na consolidação das redes urbanas coloca as sedes municipais muito mais sujeitas às condicionantes físicas do que em qualquer outra porção do território nacional. O intuito do presente item é demostrar como características de posição, sítio (base física) e redes fluviais, são ainda condicionantes na maneira com que se configuram dinâmicas de distribuição da população, usos do solo e redes urbanas em Nhamundá. O termo posição designa localização física, já situação envolve outros elementos que tornam a posição um fator vantajoso, como a presença de eixos de circulação (GEORGE, 1983, p. 40).

Localizado na porção oriental do Estado do Amazonas, o município de Nhamundá faz limites com os municípios de Parintins (AM) ao sul, Urucará a oeste, Faro (PA) e leste e ao norte com o estado de Roraima (figura 1). Possui extensão territorial de $5.751 \mathrm{~km}^{2}$ e conta com uma população de 31.593 habitantes, com densidade de 1,3 hab/Km² (Tabela 1).

Com grande extensão latitudinal (figura 1), a área municipal de Nhamundá possui três conjuntos de relevos: 1) Planície amazônica ao sul; 2) Baixos platôs da Amazônia ocidental ao centro; e 3) Planalto residual do Norte da Amazônia na faixa norte do município. Tanto as populações "rurais" como as "urbanas" estão concentradas na faixa sul do 
município, próximas à sede municipal (figura 1), fora da faixa de fronteira ao norte. Extensas áreas de várzeas sujeitas a variações sazonais fluviais (ciclos de cheias e vazantes) também fazem parte desse mosaico geomorfológico ao sul do sítio municipal, permeado de complexos flúvio-lacustres conferindo elevada piscosidade.

A proximidade dos centros urbanos e das rotas de embarcações também incentiva essa maior densidade de populações no trecho sul do município. $\mathrm{Na}$ cheia, as conexões fluviais para Parintins via lancha são realizadas em trajetos de uma hora. Na seca aumentam para duas horas, pois os canais e furos dos lagos secam e paranás mais distantes são usados para conectar as sedes. Nas secas extremas de 2009 e 2015 Nhamundá teve saída fluvial apenas para os municípios de Juruti (PA) e Terra Santa (PA) a leste da sede, favorecendo maior conectividade com tais cidades e com Manaus a oeste.

Uma das características físicas que tem tornado a faixa norte municipal quase “intocada" pelas atividades de uso de solo predatórias, são os afluentes a montante da Bacia do Rio Nhamundá, que correm em relevos mais declives, apresentando trechos de cachoeiras e afloramentos rochosos. Isso dificulta a navegação limitando entrada de embarcações maiores que incentivariam transporte de madeira, gado, formação de pasto e exploração de outros recursos.

Quanto ao sítio urbano, os aspectos geomorfológicos são condicionantes em cidades do baixo Amazonas. Três delas possuem sedes assentadas em sítios com restrições de crescimento do plano urbano. Parintins (AM) por ser um arquipélago, teve expansão recente do plano urbano para outras ilhas necessitando de aterros e pontes num rápido crescimento a partir de ocupações irregulares e novos bairros (BARTOLI, 2018 b). Barreirinha (AM) por ter maior parte do sítio urbano em várzeas (inundáveis em parte do ano), também possui limites físicos para expansão do plano urbano, com surgimento do bairro Nova Conquista oriundo de ocupação irregular, sendo inundável nas cheias.

Já Nhamundá (AM), por ter sede implantada em uma única só ilha totalmente ocupada, teve crescimento de bairros atualmente para a cidade vizinha paraense Faro (PA), localizada na margem esquerda do Rio Nhamundá, frontal à sede de Nhamundá. Uma frota de canoas com motor rabeta e botes de alumínio faz translado de centenas de pessoas diariamente entre as duas sedes, deixando clara a centralidade comercial e polarização de Nhamundá sobre Faro, que possui base econômica bem inferior à de Nhamundá. Faro funciona, portanto, como base de moradia (cidade dormitório), aos que diariamente trabalham e circulam entre as duas sedes. 
Outra particularidade do sítio é a formação de praias nos rios de águas escuras durante a estiagem, que tem sido capitaneado pelo poder público local para o turismo, ainda tímido e de visibilidade baixa, mas de alto potencial. Dois destaques ocorrem por esse atrativo, com realização da Festa do Tucunaré e recebimento de barcos de outras localidades para realização de pesca esportiva.

A porção setentrional da área municipal abrange a Terra Indígena NhamundáMapuera que possui 1.961 indígenas numa área de 1.050 ha e presença de quatro povos: Hixkaryana, Katuenayana, Katxuyana e Waiwai (figura 1). O povo mais numeroso é o Hixkaryana com 1242 habitantes no interior da TI. O subsistema territorial indígena e sua complexa territorialidade (circulação, relações com as cidades, distribuição das aldeias; presença na faixa de fronteira, etc.) serão aprofundados nos próximos textos da série de estudos do NIFFAM.

Figura 1- Municípios da sub-região do baixo Amazonas que compõem a faixa de fronteira.
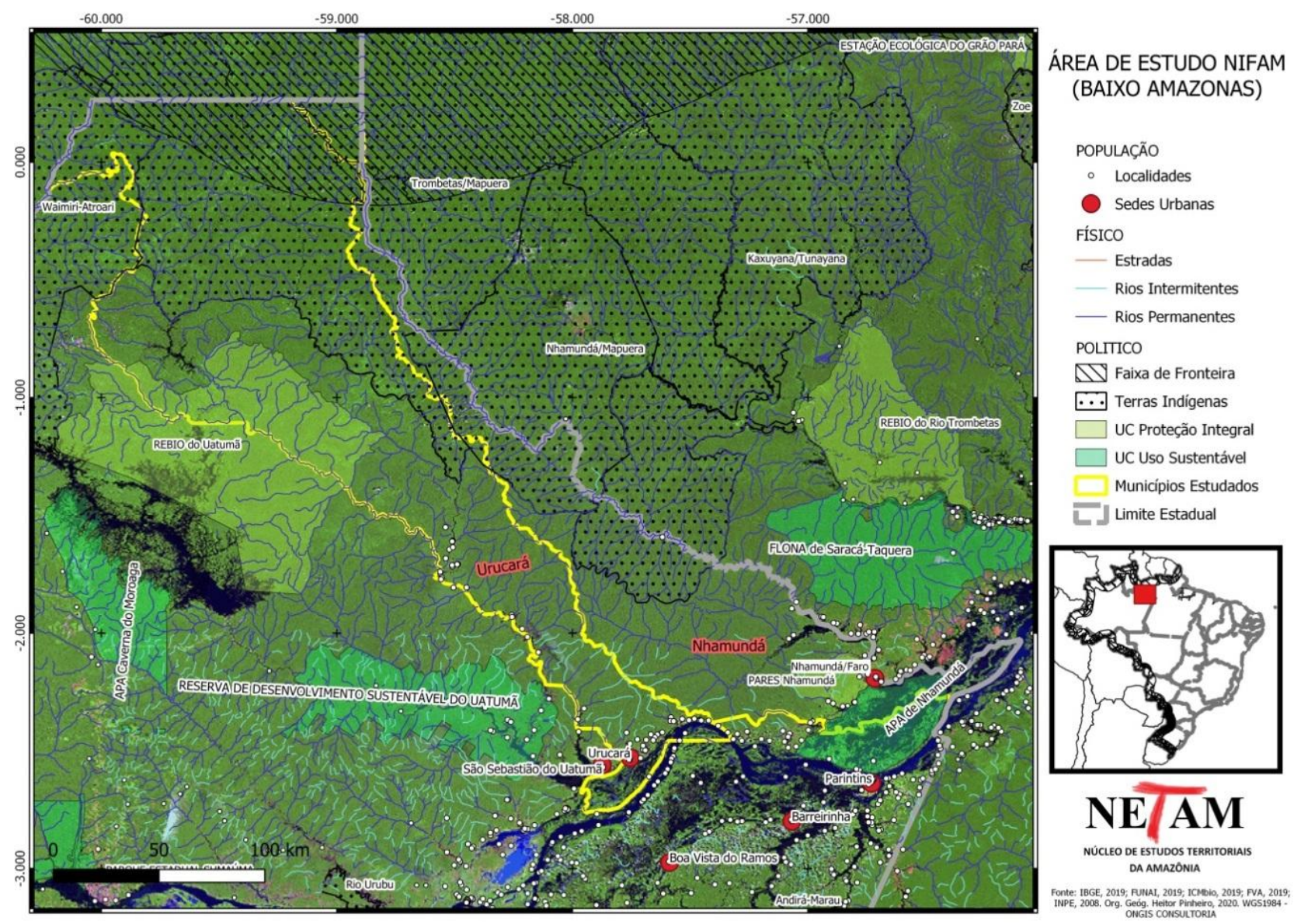

A sub-região do Baixo Amazonas, mesmo com significativa presença de populações rurais, possui baixa densidade demográfica de $2,2 \mathrm{hab} / \mathrm{Km}^{2}$, sendo que a maior densidade é doi.org/10.48075/geoq.v14i1.24480 
verificada no município de Parintins com índice de 17,1 hab/Km² e a menor densidade no município de Urucará com 0,6 hab/Km² . Apesar do patamar de cidades pequenas (exceção de Parintins considerada cidade média - BARTOLI et al, 2019), enormes áreas municipais no Baixo Amazonas permanecem com baixa densidade demográfica (Tabela 1).

A distribuição entre população rural e urbana também chama atenção. Nhamundá e Maués são os únicos municípios em que as populações rurais são mais numerosas do que as urbanas. Tais números nos colocam o desafio de pensar uma abordagem relacional que ultrapasse a dicotomia rural - urbana, necessitando de modelos analíticos que forneçam leituras sobre a interpenetração, complementaridade e sobreposição do "urbano ao rural" (e vice-versa), como propõe o modelo Sistema-Territorial Urbano-Ribeirinho apresentado a seguir.

Tabela 1 - População rural e urbana, área e densidade demográfica dos municípios do Baixo

\begin{tabular}{|l|l|l|l|l|l|}
\hline Município & $\begin{array}{l}\text { População } \\
\text { residente } \\
\mathbf{2 0 1 0}\end{array}$ & Urbana & Rural & $\begin{array}{l}\text { Área total } \\
\text { Km2 }\end{array}$ & $\begin{array}{l}\text { Densidade } \\
\text { demográfica } \\
\text { Hab./Km2 }\end{array}$ \\
\hline Parintins & 102.033 & 69.890 & 32.143 & $5.952,4$ & 17,14 \\
\hline Barreirinha & 27.355 & 12.418 & 14.937 & $5.750,6$ & 4,76 \\
\hline $\begin{array}{l}\text { Boa Vista } \\
\text { do Ramos }\end{array}$ & 14.979 & 7.550 & 7.429 & $2.586,8$ & 5,79 \\
\hline Nhamundá & 18.278 & 7.010 & 11.268 & $14.105,6$ & 1,30 \\
\hline Urucará & 17.094 & 9.886 & 7.208 & $27.903,4$ & 0,61 \\
\hline Maués & 52.236 & 25.832 & 26.404 & $39.989,9$ & 1,31 \\
\hline $\begin{array}{l}\text { São } \\
\text { Sebastião do } \\
\text { Uatumã }\end{array}$ & 10.705 & 5.904 & 4.801 & 10741,1 & 1,00 \\
\hline
\end{tabular}

Fonte: IBGE Cidades (2019).

Nesse sentido, uma questão macro surge para Nhamundá e as demais cidades pesquisadas na sub-região do baixo Amazonas: quais condicionantes físicas (relevo, hidrografia, recursos minerais, etc.) interferem na estruturação da rede urbana, na distribuição e circulação das populações e no ordenamento territorial de cada município? Como propiciam permeabilidades ou limitam acessos aos municípios que estão situados na faixa de fronteira?

Enfim, longe de defendermos que a melhor distribuição funcional da população ou a maior densidade de ocupação e uso do solo, por si só, sejam capazes de melhorar a qualidade do ordenamento territorial de vastas áreas municipais (com melhor aproveitamento de recursos), o objetivo dos estudos em andamento no Baixo Amazonas é entender como as cidades influenciam as mediações dos ordenamentos territoriais. Para isso, torna-se necessário descrever, cartografar e entender como as principais redes de sujeitos locais criam padrões de 
deslocamentos, usos do solo e usos de recursos regionais em suas complexas territorialidades "urbano-ribeirinhas".

Bitoun (2009) afirma que é necessário pensar o urbano na sua dimensão regional, reconhecendo as distinções a partir das regiões que as geram. Para o autor, as tipologias de cidades associadas a estratégias de desenvolvimento sub-regional fornecem auxílio nas especificações de propostas em políticas públicas. Ressalta que existem formas de trabalho mediadoras na produção de territorialidades - que só se realizam (ou podem ser potencializadas) através da presença da cidade. Sem esta, frações consideráveis do território permaneceriam em "desuso".

$\mathrm{O}$ acesso a recursos naturais em cada sub-região do estado do Amazonas tem sido elemento trivial na maneira com que redes locais de poder se fortalecem, usando cidades enquanto nódulos estratégicos de ações de setores político-econômico dominantes, delimitando territórios de influência: capacidade de controlar e configurar fixos e fluxos (SANTOS, 2006) necessários para reprodução de determinada atividade. Prefeitos, elites locais e configurações variadas entre empresas com atuações em escalas diversas, são geralmente os principais beneficiários. Obviamente são escalas de exploração e quantidade de riquezas diferenciadas em cada sub-região, variando das bilionárias jazidas de gás e petróleo dos municípios da calha do Solimões, às pequenas extrações locais de ouro e madeira no baixo Amazonas em rápida e preocupante proliferação.

Pelas características litológicas que compõem a Bacia Hidrográfica do rio Nhamundá atravessando o município de noroeste a sudeste, há presença de areia e seixo pela proximidade de escudos rochosos na faixa central do município, propiciando exploração e acumulação de capital de frações dominantes na cidade e enorme interesse de empresas transnacionais pela liberalização da exploração de jazidas de minérios (Quadro 1). Nos últimos anos, tem ocorrido extração ilegal de areia e seixo em Nhamundá beneficiando elites locais e setores políticos dominantes ${ }^{4}$. Tais padrões de enriquecimento de setores do capital mercantil com baixo processamento dos recursos na cidade e altos impactos ambientais e humanos, se repetem em grande parte do estado do Amazonas.

\footnotetext{
${ }^{4}$ https://correiodaamazonia.com/pf-prende-prefeito-de-nhamunda-por-extracao-ilegal-de-seixo/. Acessado em: $05 / 12 / 2019$.
} 
Quadro 1 - Relação das áreas de relevante interesse mineral (ARIM) do município de Nhamundá.

\begin{tabular}{|l|l|}
\hline Classe Utilitária & Substância / Contexto Geológico \\
\hline $\begin{array}{l}\text { Minerais } \\
\text { Metálicos }\end{array}$ & $\begin{array}{l}\text { 1 - Alumínio (bauxita): Jazimento de alteração da Formação Alter do Chão, } \\
\text { com crosta laterítica. } \\
\text { 2 - Ferro: Jazimento de alteração da Fm. Nhamundá do Grupo Trombetas. }\end{array}$ \\
\hline Insumos Agrícolas & $\begin{array}{l}\text { 3 - Calcário do Jatapu (calcário, ferro } \\
\text { e gibsita): Jazimento associado às formações Itaituba e Nova Olinda, Bacia do } \\
\text { Amazonas. }\end{array}$ \\
\hline $\begin{array}{l}\text { Materiais de Uso } \\
\text { na Construção Civil }\end{array}$ & 4. Seixo e areia. Depósitos aluvionares do rio Nhamundá. \\
\hline
\end{tabular}

Fontes: Dados de províncias, distritos, minas, jazidas, depósitos, ocorrências, indícios e áreas potenciais modificados do SIG Geologia e Recursos Minerais do Amazonas (REIS et al., 2006); títulos minerários (disponível em: <http://www.dnpm.gov.br>. Acesso em: jun. 2009); Anuário Mineral do Departamento Nacional de Produção Mineral (disponível em: <http://www.dnpm.gov.br〉. Acesso em: ago. 2008).

As pressões para liberação de exploração de minérios em Terras Indígenas tem sido constantes, entre elas o Projeto de Lei PL 1610/96 considerado uma afronta à soberania dos povos indígenas ${ }^{5}$ ao sugerir mudanças no artigo 231 da Constituição Federal, que proíbe a mineração em Terra Indígena e desrespeita a Convenção 169 da Organização Internacional do Trabalho (OIT) $)^{6}$ da qual o Brasil é signatário.

\section{Redes regionais e situação da sede urbana de Nhamundá}

As mediações logísticas de distribuição de produtos industrializados pelas redes urbanas das quais Nhamundá participa, se realizam primordialmente pelo transporte fluvial. A quantidade de produtos que entra no município ocorre por três tipologias de embarcações (Quadro 2): três Ferry Boats (FB), três navios de ferro (NM - navio motor), cinco barcos de madeira (BM - barco motor). Sendo polarizada por três eixos de competição na rede urbana possuindo maior pujança econômica (Manaus a leste, Parintins ao sul e rede urbana paraense a leste), ocorre desestímulo para investimentos produtivos locais frente à forte competição de produtos das redes urbanas regionais e nacionais, inclusive alimentos como hortifrutigranjeiros que são importados a partir da rede urbana paraense com custos similares aos produzidos localmente, segundo sinalizaram entrevistas em feiras e comércios.

\footnotetext{
5 http://www.ihu.unisinos.br/entrevistas/544409-lei-da-mineracao-em-terras-indigenas-uma-nova-tentativa-detutelar-os-indigenas-entrevista-especial-com-carlos-bittencourt. Acessado em: 14/12/2019.

${ }^{6}$ http://www.planalto.gov.br/ccivil_03/_ato2004-2006/2004/decreto/d5051.htm. Acessado em: 06/12/2019.
} 
Com a crescente quantidade de pessoas acessando Parintins, as antigas embarcações de madeira estão sendo substituídas paulatinamente por lanchas de alumínio (denominadas como "expresso" ou "a jato") ou navios de ferro. Os percursos que eram realizados em quatro horas ou mais pelos barcos de madeira foram reduzidos para uma hora ou uma hora e meia, dependendo da sazonalidade. As lanchas que realizam tais percursos revezam horários para atender a população possuindo mesmo trajeto. $\mathrm{Na}$ enchente as lanchas cortam caminho através dos canais que transbordam do complexo de lagos da APA do Macurycanã. Na vazante ("seca"), o caminho torna-se mais extenso sendo necessário seguir pelo Paraná do Cabury até Parintins.

As transformações nesse tipo de transporte afetam a centralidade tanto de Nhamundá como das comunidades conectadas no trajeto. Não existem estradas para tais conexões, sendo necessário que os fluxos restantes sejam feitos por outras "linhas" fluviais complementares. Algumas estradas de terra conectam comunidades, com fluxo maior no período de estiagem, quando várzeas podem ser percorridas por motocicletas.

$\mathrm{O}$ quadro 2 demonstra que as embarcações maiores (FB e NM) são predominantemente utilizadas ligando Nhamundá aos polos de nível hierárquico superiores na rede urbana: Manaus, Santarém e Belém, esta última indiretamente, pois abastece Santarém. Cabe lembrar que Santarém funciona como nódulo de distribuição de produtos advindos do agronegócio no Centro Oeste brasileiro através da BR-163, que a liga a Cuiabá (MT). Isso amplia a penetração de produtos advindos de localidades cujos custos de produção são menores, o que a caba fragilizando ainda mais a economia local incapaz de disputar com preços de mercadorias oriundas dos complexos agroindustriais do restante do país. É aspecto necessário considerar as hierarquias inter-regionais na análise de pequenas cidades, pois o comando maior desse processo está fora dos espaços de análise "tornando-se impositivo estudar a natureza das hierarquias (impostas em variadas escalas) de geração e apropriação de riqueza" (BRANDÃO, 2007, p. 48). São elementos que sinalizam forças coercitivas exógenas e macroeconômicas como concorrências/rivalidades entre agentes capitalistas e forças oligopólicas (BRANDÃO, 2007, p. 52).

Parte das embarcações maiores pertence a grupos econômicos dominantes de Nhamundá, que assim como os setores mercantis de Parintins, conquistam vantagens nos preços dos produtos trazidos de fora, o que lhes confere preços mais baixos na competição local. Esse sistema territorial dominante é nomeado como Urbano-Fluvial (STUF), que 
necessita das embarcações da economia popular (STUR) para posterior distribuição para interiores.

A quantidade de lanchas e embarcações de madeira menores (BM) demonstra a intensa polarização exercida por Parintins que exerce função de responsabilidade territorial. Portanto, tipologias de embarcações sinalizam a maneira com que Nhamundá tem sido inserida no processo de circulação regional e distribuição de produtos. Surge uma hipótese a ser aprofundada em estudos futuros, a de que Nhamundá utiliza a rede para "complementar" sua economia: Santarém fornecendo produtos alimentícios e agropecuários, Manaus produtos industrializados e Parintins serviços. A rede paraense é também compradora de castanha e pescado, e Parintins absorve parte do gado em seu matadouro.

Quadro 2 - Embarcações que atendem Nhamundá.

\begin{tabular}{|l|l|l|}
\hline Tipo /embarcação & Nome da embarcação & Translado semanal \\
\hline \multirow{4}{*}{ Ferry Boat (FB) } & FB Ana Rebeca & Santarém \\
\cline { 2 - 3 } & FB Nhamundaense & Manaus \\
\cline { 2 - 3 } & FB Sereia & Manaus \\
\hline $\begin{array}{l}\text { Navio de ferro } \\
\text { NM - navio } \\
\text { motor) }\end{array}$ & NM Cidade de Nhamundá & Manaus \\
\cline { 2 - 3 } Barco de madeira & NM Cidade de Oriximiná & Santarém \\
\cline { 2 - 3 }$\left(\begin{array}{l}\text { BM - barco } \\
\text { motor) }\end{array}\right.$ & NM Cid. Terra Santa & Santarém \\
\cline { 2 - 3 } & BM São Vicente & Parintins \\
\cline { 2 - 3 } & BM Princesa Gaby & Parintins \\
\cline { 2 - 3 } & BM Dona Eva Jack & Santarém \\
\cline { 2 - 3 } & BM Tio Tavares (sai para) & Parintins \\
\hline \multirow{4}{*}{ Lanchas } & L. Lana Rafaella & Parintins \\
\cline { 2 - 3 } & Lancha Expresso JG & Panaus \\
\cline { 2 - 3 } & Lancha Dona Jô II & Parintins \\
\cline { 2 - 3 } & Lancha Dona Jô IV & Parintins \\
\hline
\end{tabular}

Fonte: trabalho de campo (10/2019).

Nesse sentido, o espaço geográfico possui no processo de urbanização o nervo essencial de intermediação das relações de dominação, como apontam Santos e Silveira (2003), onde produtos mais rentáveis recebem primazia em relação a outros, causando desvalorização de certas atividades em favor de outras, inserindo uma especialização espacial. A especialização geográfica da produção é responsável por uma massificação do capital, que “impõe ao mercado uma escala espacial mais ampla, e pode-se tanto falar de uma alienação regional como de uma alienação do homem-produtor" (SANTOS \& SILVEIRA, 2003, p. 145), causando colapso em cidades locais.

No estado do Amazonas, esse processo foi dinamizado pela criação da Zona Franca e a posterior criação do Polo Industrial de Manaus, que impactaram negativamente as 
economias de pequenas cidades interioranas (BECKER, 1974). Mesmo com boas intenções do Planejamento Estratégico da SUFRAMA em “[...] aprimorar o processo de interiorização dos efeitos do modelo Zona Franca de Manaus" (Relatório de Gestão SUFRAMA, 2007, p.13), as desigualdades espaciais se aprofundaram.

Essa transformação gerou mudanças espaciais na cidade de Manaus com reflexo em todo o estado, especialmente nas cidades da calha do Amazonas. Pretendendo "fomentar a produção no interior da região, com agregação de valores através de indústrias vinculadas que aumentem a produção, a atividade econômica e renda regional", tal quadro esteve longe de se concretizar nos municípios interioranos. Fica latente na disparidade de população, renda e desenvolvimento humano entre a capital Manaus comparada às cidades pequenas da subregião de planejamento do baixo Amazonas, ou até mesmo com a segunda maior cidade do estado, Parintins.

Tabela 2 - Características sociodemográficas de municípios do baixo Amazonas e a metrópole Manaus.

\begin{tabular}{|l|l|l|l|l|l|l|}
\hline Município & População & $\begin{array}{c}\text { PIB per } \\
\text { capita (R\$) }\end{array}$ & $\begin{array}{c}\text { Pessoal } \\
\text { ocupado }\end{array}$ & \multicolumn{1}{|c|}{ IDH } & $\begin{array}{c}\text { Mortalidade } \\
\text { infantil } \\
\text { (óbitos por mil } \\
\text { nascidos } \\
\text { vivos) }\end{array}$ & $\begin{array}{c}\text { Esgotamento } \\
\text { sanitário } \\
\text { adequado } \\
\text { (\%) }\end{array}$ \\
\hline Urucará & 16.383 & $17.378,65$ & 882 & 0,620 & 11,11 & 10,9 \\
\hline $\begin{array}{l}\text { Boa Vista } \\
\text { do Ramos }\end{array}$ & 18.781 & $6.089,15$ & 685 & 0,565 & 12,54 & 29,7 \\
\hline Barreirinha & 31.593 & $7.059,80$ & 954 & 0,574 & 14,94 & 4,3 \\
\hline $\begin{array}{l}\text { São } \\
\text { Sebastião do } \\
\text { Uatumã }\end{array}$ & 13.685 & $7.232,53$ & 536 & 0,577 & 19,42 & 1,7 \\
\hline Nhamundá & 20.899 & $6.462,02$ & 888 & 0,586 & 16,76 & 16,1 \\
\hline Maués & 62.755 & $6.481,40$ & 3.574 & 0,588 & 16,74 & 27,1 \\
\hline Parintins & 113.168 & $9.092,68$ & 6.974 & 0,658 & 22,91 & 19,3 \\
\hline Manaus & $\mathbf{2 . 1 4 5 . 4 4 4}$ & $\mathbf{3 3 . 5 6 4 , 1 1}$ & $\mathbf{5 0 5 . 6 8 2}$ & $\mathbf{0 , 7 3 7}$ & $\mathbf{1 4 , 5 2}$ & $\mathbf{6 2 , 4 \%}$ \\
\hline
\end{tabular}

Mello e Silva (2010) destaca que os benefícios do processo de crescimento econômico, num sentido geral, não estão sendo distribuídos de forma justa (ou equilibrada) sobre todo o espaço geográfico, salientando agravantes nas diferenças de renda per capita e da qualificação do capital humano que são acentuadas pelos desequilíbrios espaciais. A busca por equidade espacial, teoricamente, é a maximização do acesso a todos os componentes do bem-estar social por parte de uma determinada população, a partir de seus padrões espaciais (MELLO e SILVA, 2010, p. 112). Outras disparidades chamam atenção na Quadro 2, com o PIB per capita da capital Manaus ultrapassando o triplo do PIB per capita de Parintins e mais 
que o quíntuplo do PIB per capita de Nhamundá. Esgotamento sanitário é outro aspecto que demonstra o abandono das políticas públicas para os interiores.

\section{Centralidade comercial e sistemas territoriais de Nhamundá}

A estrutura de relações reticulares de Nhamundá a partir de seus Sistemas Territoriais é condicionada pela situação da cidade: "um espaço geográfico relativizado que se molda em função das técnicas, das estruturas econômicas e sociais e dos sistemas de relações. É uma dinâmica processual que leva em conta redes e fluxos diversos a partir de um processo de centralização" (DAMIANI, 2006).

Para Mello e Silva (2010), a questão da centralidade é discutida no contexto do que poderia ser chamado de estruturação/reestruturação produtiva, retomando textos clássicos que evidenciam que as cidades e as estradas criam a região, sendo, portanto, organismos que dirigem o abastecimento regional (LA BLACHE, 1920). A centralidade é considerada como nível de oferecimento de funções centrais por parte de uma determinada cidade para si mesma e para sua região, cujos bens e serviços centrais são oferecidos necessariamente em poucos lugares centrais (conforme indica a teoria de CHRISTALLER - 1968 apud MELO E SILVA, 2010).

Como na maioria das cidades interioranas do Amazonas, Nhamundá não gera receitas significativas pela baixa capacidade de produção/arrecadação, sendo dependente de repasses governamentais. Possui a posição de $45^{\circ}$ PIB do Estado (dos 62 municípios), com cerca de 0,14\% do PIB de todo o Estado em 2016 (SEBRAE, 2019). Segundo relatório do SEBRAE (2019), o setor público tem papel relevante no desenvolvimento do município, chegando a contemplar 59,02\% do PIB local, juntamente com o Setor de Comércio e Serviço $(19,22 \%)$. Os demais setores que contribuem são o setor Agropecuário (17,44\%) e o de Indústria (4,32\%). Maior parte de empresas formalizadas estão concentradas nos setores de comércio e serviços. As sete principais atividades desenvolvidas no Município são as de comércio de produtos alimentícios - minimercados; comércio de artigos de vestuário e acessórios; comércios de bebidas; lanchonetes, casas de chá, sucos e similares; entre outros (SEBRAE, 2019). A combalida economia urbana, insuficiente para suprir atividades que abarquem a população local, cumpre número limitado de funções atendendo populações que realizam deslocamentos semanais para a cidade, formando uma complexa economia popular 
em interação com os setores dominantes do comércio passíveis de serem entendidos pelo modelo STUR.

O STUR demonstra o comportamento espacial dos circuitos da economia popular inseridos em contexto específico, ocorrendo práticas espaciais cujo recorte analítico priorizou em estudos anteriores áreas de influência da cidade de Parintins. Apesar de privilegiar a dinâmica sub-regional e intraurbana no modelo STUR, é preciso considerar dinâmicas transescalares para melhor detalhamento das complexas relações existentes com a rede urbana regional (com forte influência da metrópole Manaus em disputa com a rede urbana paraense) e as escalas nacionais e globais. Tais conexões acabam sendo evidenciadas pelo tipo de bens industrializados que são distribuídos para os interiores.

A proposta metodológica do Sistema Territorial Urbano-Ribeirinho (STUR) apresentada em Bartoli (2017, 2018a, 2018b, 2019a) contribui para analisar como as redes de sujeitos locais de Parintins (AM) vieram se re-territorializando na cidade devido à instabilidade dos ciclos econômicos que ocorreram na região, gerando êxodo rural e intensa circulação entre cidade e interiores. Constata-se que as redes de sujeitos que manejam recursos regionais como coletivos organizados desempenham novas mediações na formação de territórios e territorialidades. A partir da formação de projetos econômicos com reformulações organizacionais diversas e maior interação com esferas variadas na cidade (dimensões políticas, econômicas, culturais e naturais), essas redes de sujeitos constituem um padrão de circulação formando redes diversificadas em busca de complementos para a combalida economia urbana.

Dinamizado por populações que se estabelecem nas cidades, moldando espaços intraurbanos e realizando intensos deslocamentos com as áreas de entorno, o papel mediador que o STUR aparece em cinco vertentes que são apresentadas em Bartoli (2017; 2018a; 2018b): i) zonal e topológico: conectando a cidade por meio de redes temáticas a pontos diversos do entorno sub-regional através da navegação fluvial; ii) produção e configuração do espaço urbano em bairros oriundos de ocupações irregulares e de fragmentos do espaço intraurbano, constituindo fixos úteis para a navegação (beiras de rios populares, por exemplo); iii) econômico dual e complementar: sendo dinamizado principalmente pela economia popular, mas em interação constante com as esferas de valorização do capital mercantil dominantes na cidade (saltos escalares ocorrem em relações diversas que ultrapassam a subregião); iv) organizacional e institucional: outros tipos de coalizão de sujeitos ganham relevância (cooperativas, associações, colônias de pescadores, etc.), mediando ações que se 
desdobram em práticas sobre o território; v) simbólico-cultural: traços da cultura cabocla e ribeirinha, indígena ou de conhecimentos populares são absorvidos e resignificados pela inserção ao processo urbano.

Dentro do setor primário, três subsistemas territoriais dinamizam interações entre STUF / STUR modelando os fluxos nas redes urbanas em que Nhamundá se insere: pescado, gado e produção de mandioca/farinha. O sindicato rural local possui cadastradas 4.813 pessoas, com 2.300 trabalhadores ativos hoje, os demais recebendo aposentadoria rural. Revendo a tabela 1, o predomínio da população rural sobre a urbana tem como base o acesso constante à cidade compondo a circulação do STUR, tendo apoio numa nova realidade: a recente presença de energia nas comunidades abastecida a partir do Programa Luz para Todos nos governos dos Presidentes Luiz Inácio Lula da Silva e Dilma Rousseff (de 2003 a 2016). As comunidades mais citadas nas entrevistas que realizam comércio frequente com a cidade, por ordem de grandeza foram: 1 - Cutipanã; 2 - Juruá estrada; 3 - Aldeia Caçauá (com cerca de 400 famílias); 4 - Santa Maria do Mamuriacá; e, 5 - Sagrado do Aruaçú.

As setas do quadro 4 indicam a influência de um sistema territorial sobre o outro, onde o STUR fornece produtos para o STUF, e este realiza exploração dos sujeitos do STUR fornecendo mercadorias a preços altos e comprando itens regionais a preços baixos. $\mathrm{O}$ processamento de produtos regionais na cidade pelos setores populares da economia movimentada no interior do STUR ainda é baixo. Identificamos em trabalho de campo seis movelarias de pequeno porte abastecendo somente o mercado municipal com móveis domésticos e esquadrias. Quatro pequenos estaleiros navais popularmente conhecidos como Tilheiros fabricam pequenas embarcações de madeira e realizam trocas de tábuas e diversos reparos. As tipologias de embarcações descritas em Bartoli (2017; 2018b) variam de forma marcante quanto ao uso/função, tipo de carga e lugares acessados. São conectores e mediadores do STUR, muito presentes na paisagem de cidade com dinâmicas ribeirinhas.

Sobre os subsistemas indígenas que possuem maior relação com a cidade e a rede urbana, se destacam as vendas de banana e a castanha, esta última com 10.000 produção de hectolitros por ano de acordo com relatórios do Instituto de Desenvolvimento Agrário do Amazonas (IDAM, 2019). A usina de castanha hoje desativada faz com que a rede urbana paraense absorva a castanha de Nhamundá.

Outro destaque refere-se ao subsistema da pecuária bovina e bubalina. O rebanho existente é de 22.439 bovinos e 2.868 bubalinos. No período da enchente (março a agosto) e no período da vazante (agosto a fevereiro), devido a entrada de criadores dos municípios 
paraenses de Faro, Terra Santa, Juruti e da vizinha Parintins (AM), ocorre aumento do rebanho para 60.000 bovinos e 4.000 bubalinos. Estão distribuídos em 501 propriedades, 494 criadores que permanecem no município o ano todo tendo 1.020 ha de pastagens em terra firme e 1.530 ha em várzea.

Quadro 4 - Conexões entre os sistemas territoriais mediados pela cidade.

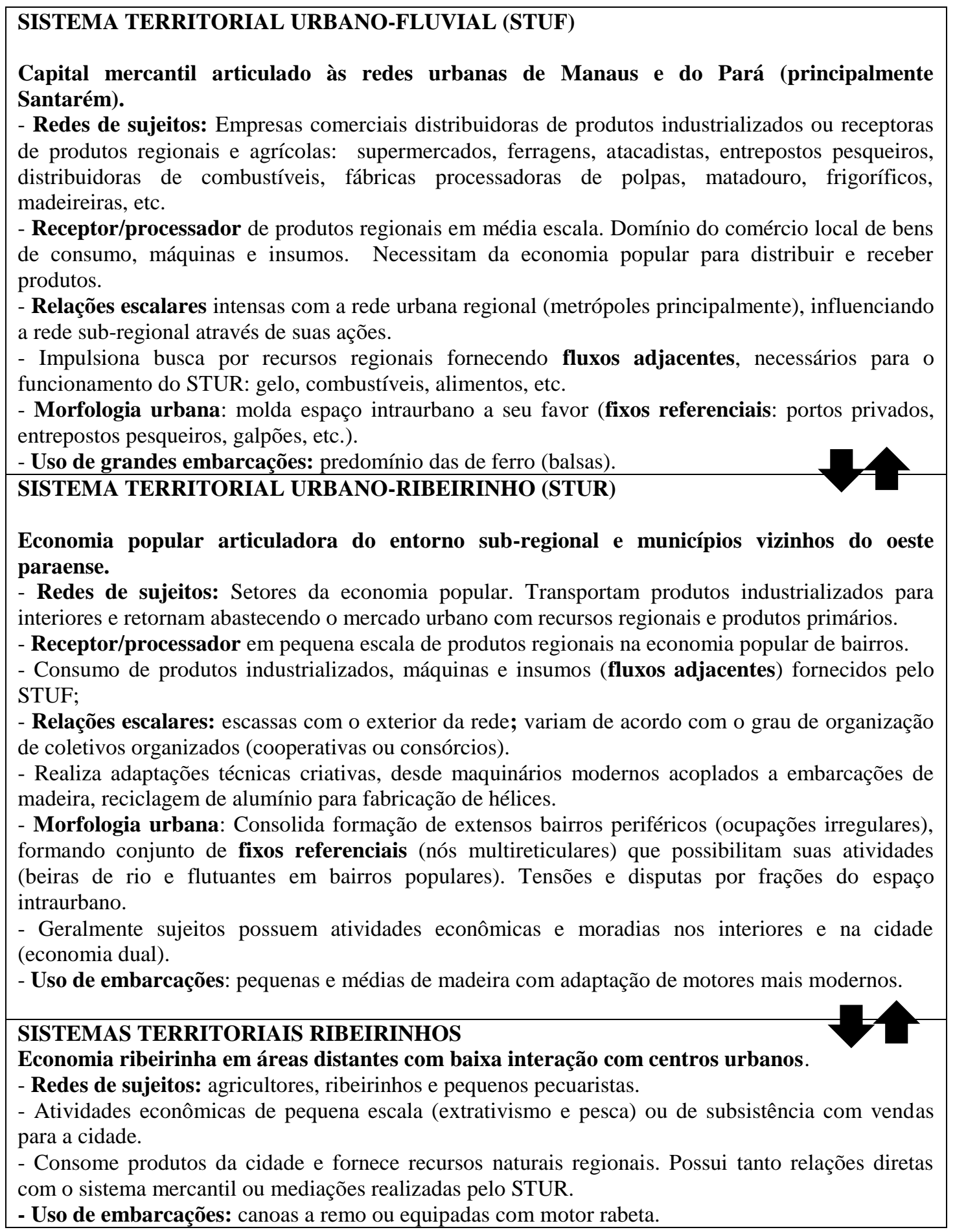


$\mathrm{Na}$ maioria são pequenos criadores, que também compõem a dinâmica de complementação entre STUR e STUF, onde um comércio especializado em produtos agropecuários é encontrado em Nhamundá, além das mais importantes feiras e festas locais tendo a produção pecuária como pano de fundo.

O subsistema pesqueiro, por estar inserido na demanda urbana de pescados, necessita de produtos considerados como fluxos adjacentes fornecidos pelo STUF (quadro 4): gelo, gasolina, financiamentos/empréstimos informais, fornecimento de cestas básicas, etc.

Devido à posição próxima da sede ao rio Amazonas com abundância de lagos, rios e paranás, a piscosidade ao sul da sede municipal é enorme. Urucará possui dois sindicatos e uma colônia de pescadores. De acordo com a presidente da Colônia Z-48, 580 pescadores estão cadastrados com 280 recebendo seguro defeso. Outra instituição que fornece seguridade aos pescadores é o Sindicato local, com 250 pescadores cadastrados. A presença desse tipo de auxílio é de grande importância para a economia local. Com 2 barcos grandes pertencentes aos pescadores e financiados pelo Banco da Amazônia (BASA), as áreas de maior piscosidade são os lagos ao sul do núcleo urbano e eventualmente o rio Nhamundá (águas escuras) pela presença de espécies migratórias. Os lagos mais frequentados citados foram Xixiá, Mondongo, Virasaia, Acari, Arnacurú, Curiá, Taperebá e Lago Grande.

De janeiro a maio a principal pesca é de matrinxã e jaraqui que migram do rio Nhamundá em direção ao rio Madeira. A espécie vaqueta também é abundante e muito citada nas entrevistas. A descrição dessa migração e a maneira com que a atividade pesqueira se movimenta "animando" a rede urbana são passíveis de estudos futuros. De maio a junho predomina pesca do tucunaré, aracu, curimatã, cuiú, surubim e dourada. Metade das vendas é destinada para os mercados de Nhamundá, e metade para os municípios limítrofes do Pará Faro e Terra Santa.

As mediações da cidade no setor pesqueiro para melhor processamento e manejo do pescado são tímidas, ocorrendo acordos de pesca apenas na comunidade de Santo Antônio do Mamuriacá, e outro acordo em andamento no rio Nhamundá. Acordos de pesca são essenciais para resguardar estoques pesqueiros de barcos que invadem a sub-região vindos do Pará e de Parintins (BARTOLI, 2019b).

Há dificuldade de obtenção de gelo pelos pescadores locais, com uma única fábrica pertencente ao prefeito cujo preço da saca está acima da média das cidades ao redor, com gelo de qualidade ruim em escamas pequenas. Um dado positivo foram dois projetos enviados pela Colônia para a Secretaria de Produção do Estado do Amazonas (SEPROR) para obtenção de 
fábrica de gelo. Outra reclamação é relativa à ausência de feira para melhoria das vendas dos pescados, que possuem apenas um box na feira municipal. Pescadores costumam vender em caixas de gelo nas esquinas da cidade, claramente compondo a função do STUR de abastecer/complementar a economia urbana.

\section{Considerações finais}

Os aspectos do sítio e situação são de suma importância na distribuição atual da população de Nhamundá e dos usos do solo, com a presença de alto potencial de exploração de recursos naturais futuramente, mas que dependem de melhorias no nível de mediações urbanas para maior controle do ordenamento territorial com qualidade ambiental. A inserção de Nhamundá na rede urbana tem desestimulado a produção agrícola local impelindo o papel de entreposto comercial à sede, fortalecendo setores dominantes do capital mercantil. Nhamundá passa a ter sua renda drenada por outras localidades, devido ao consumo de produtos diversos através do transporte fluvial. O perfil de mediações urbanas e relações na rede tornam os papéis de ordenamento territorial exercidos pela cidade insuficientes. Como indicador inicial para o aprofundamento de pesquisas futuras, almeja-se diagnósticos mais precisos com participação de redes de sujeitos locais visando formulação de políticas públicas para a faixa de fronteira, consideramos que:

- é necessário estímulo para formação de coletivos organizados (cooperativas, associações de produtores, consórcios, etc.), melhorando a capacidade produtiva, o processamento de recursos e propiciando maior agregação de valor a produtos, além da geração de renda e ocupação laboral local.

- a densa presença dos setores populares que compõem o STUR deve ser potencializada em diversas frentes, melhorando a presença de instituições de fomento produtivas (EMBRAPA, por exemplo), estimulando absorção e processamento pela cidade de produtos que estão sendo enviados para outras cidades, como a castanha, o pescado e o gado.

- a preservação/conservação da faixa de fronteira (incluindo a participação ativa indígena), depende da maneira com que a economia urbana possa se fortalecer e se manter com seus próprios recursos, evitando exercer pressão sobre as áreas a montante do rio Nhamundá. 
Tais melhorias nas mediações de ordenamento territoriais exercidos pelo nódulo referencial de relações de poder (a cidade e suas redes de sujeitos), evitariam discursos que estimulam a ocupação de terras a montante da Bacia do rio Nhamundá, tornando a faixa de fronteira um trunfo para repensar o desenvolvimento regional.

\section{Referências}

BARTOLI, E. O Retorno ao Território a partir da cidade: Sistemas Territoriais UrbanoRibeirinhos em Parintins (AM). Presidente Prudente: PPGG / UNESP, 2017 (Tese de Doutorado).

. Cidades na Amazônia, Sistemas Territoriais e a Rede Urbana. Mercátor, v. 17, e17027, p. 1-16, 2018a.

Entre o Urbano e o Ribeirinho: Territorialidades Navegantes e Sistemas Territoriais em Parintins (AM). Espaço Aberto, PPGG - UFRJ, Rio de Janeiro, v. 8, n.2, p. 169-185, $2018 b$.

Territorialidades Urbano-Ribeirinhas: o Sistema Territorial pesqueiro de Parintins (AM). GeoNorte, v.13, 2019a.

Tilheiros: carpintaria naval e sistemas territoriais em Parintins-AM. In: Revista Desenvolvimento Meio Ambiente, v. 51, Seção especial: Técnica e Ambiente, p. 43-62, agosto $2019 b$.

BARTOli, E. SCHOR, T. OliveIRA, J. A., Cidades Médias na Amazônia: ampliando percepções sobre a responsabilidade territorial de Parintins (AM). Terra Plural, 2019.

BECKER, B. K. O Uso Político do Território: questões a partir de uma visão do Terceiro Mundo. in: BECKER, B. K. COSTA, R. H. SILVEIRA, C. D. B. (orgs.). Abordagens Políticas da Espacialidad $e$. Rio de Janeiro: UFRJ, 1974.

BRANDÃO, Carlos Antônio. Território e Desenvolvimento: as múltiplas escalas entre o local e o global. Campinas: Editora da Unicamp, 2007.

BITOUN, J. Tipologia das cidades brasileiras e políticas territoriais: pistas para reflexão. in: MIRANDA, L. (orgs.). Desenvolvimento e Cidades: Contribuições para o Debate sobre as Políticas de Desenvolvimento Territorial. Rio de Janeiro: FASE, Observatório das Metrópoles, 2009.

DAMiAnI, A. L. Cidades Médias e Pequenas no Processo de Globalização. In: América Latina: cidade, campo e turismo. CLACSO: São Paulo, 2006.

GEORGE, Pierre. Geografia Urbana. São Paulo: Difel,1983. 
IDAM. Instituto de Desenvolvimento Agropecuário e Florestal Sustentável do Estado do Amazonas. Plano Operativo das Unidades Locais do exercício, Nhamundá: 2019.

MELLO e SILVA. Sylvio Bandeira de. Cidades pequenas e médias: reflexões teóricas e aplicadas. In: Cidades médias e pequenas: teorias, conceitos e estudos de caso. / Diva Maria Ferlin Lopes, Wendel Henrique (organizadores). - Salvador: SEI, 2010. 250 p. il. (Série estudos e pesquisas, 87).

SANTOS, M. SILVEIRA, M. L. Brasil: território e sociedade no limiar do século XXI. Rio de Janeiro: Record, 2003.

SEBRAE/ AM - Serviço de Apoio às Micro e Pequenas Empresas do Estado do Amazonas. PERFIL DOS MUNICÍPIOS DO ESTADO DO AMAZONAS, 2019. ONLINE: www.datasebrae.com.br/am

SUFRAMA. Relatório de Gestão. Ministério do Desenvolvimento Indústria e Comércio Exterior, 2007. Disponível em http://www.suframa.gov.br/suframa_relatorio_de_gestao.cfm VIDAL DE LA BLACHE, P. La France de l’ Est. Paris: Armand Colin, 1920.

Artigo recebido em 07-04-2020 Artigo aceito para publicação em 21-02-2021 